\title{
FORMATION OF DUSTY STRUCTURES IN SPHERICAL GLOW DISCHARGE
}

\author{
A.I. SCHERBINA, S.V. BURDYUKH \\ Petrozavodsk State University, Research and Educational Center on Basic Problems \\ of Application of Low Temperature Plasma Physics \\ burduch@ onego.ru,dusty@ plasma. karelia.ru)
}

PACS 71.20.Nr; 72.20.Pa (10, Universitetskaya Str., Petrozavodsk 185910, Russia; e-mail:

(C) 2011

\begin{abstract}
We study, for the first time, plasma-dust structures in the spherical geometry of a discharge, which are formed either spontaneously or specially. High molecular gases, such as acetone and ethyl alcohol, are used for the generation of strata. Strata are required for the formation of structures of injected grains. The generation of grains in air plasma occurs spontaneously, and a structure is formed around the anode, when strata are not observed. Experiments were carried out in the range of pressures $30-100 \mathrm{~Pa}$ at a discharge current of 20-30 mA. To control the chemical composition of the gas environment, mass-spectrometry is used.
\end{abstract}

Nowadays, most of the experiments on dusty plasma research are carried out in rf and glow discharges. The study of the dust structures under the conditions different from classic ones may provide a new information on physical processes and parameters causing their formation. Spherical glow discharge plasma may serve as an example of such conditions. Differences in the discharges of cylindrical and spherical geometries result in differences in plasma characteristics. The present work is aimed at the formation and the research of dust structures in a spherical glow discharge and at the study of a spherical glow discharge itself. A mass-spectrometer was used for monitoring the plasma-forming medium of a discharge.

In [1], the striations in a spherically symmetric gas discharge were first registered experimentally. Geometrical differences in the discharges in tubes and those of the spherical geometry result in differences in plasma characteristics, the most important ones are as follows: the current density in the linear example is constant along the current lines, while it increases toward the central electrode in a spherical discharge, and the recombination processes at the discharge in tubes mainly occur on the tube walls. In the spherical case, the recombination may occur only in the volume. Moreover, due to the radial inhomogeneity of a spherical discharge, the total current is determined not only by the drift of electrons in an electric field, but also by their diffusion [2].

The experimental setup consists of an oil-free backing pump SD-5D, a turbomolecular pump TW-70H, a system of control over the residual pressure (vacuum gage VIT-3) and the working pressure (Baratron Type 626A), and a system of working gas puffing CHA-1. For the purpose of the discharge gaseous medium control, the bench is provided with a radio frequency mass-spectrometer of the MX-7303 type (resolving power of $1 \mathrm{amu}$, mass range of 2-400 amu) supplemented with a digital system for the mass spectrum registration.

The spherical discharge was formed in an experimental chamber consisting of a bell glass $250 \mathrm{~mm}$ in diameter and a metal base with holes providing the air pumping and the gas puffing to the chamber and to the massspectrometer. A close-meshed net made of stainless steel and functioning as a cathode was placed along the walls inside the camera making the discharge observation possible. An anode of $7 \mathrm{~mm}$ in diameter made of steel was placed at the center of the camera. The metal rod, on which the anode was fixed, was coated with isolation of a quartz tube. A container with a net was applied for the injection of dust particles into the discharge. Shaking the container was performed with a motion vacuum feed-through.

The discharge area, in which the dust particles were expected to appear, was illuminated by a laser LCSDTL-318 (a wavelength of $532 \mathrm{~nm}$, and the maximum power of $200 \mu \mathrm{W})$ providing an opportunity to observe the particles. The laser light was stretched to a narrow beam by two cylindrical lenses. The sections of dust structures by a laser beam were recorded with a camera Canon EOS 10D or a video camera Sony DCR-HC90E. Attempts to discern separate particles using a microscope "Altami" CM-II with 10-65X magnification and a working distance of $118 \mathrm{~mm}$ were made.

The observation of the discharge in air at a pressure of 30 to $100 \mathrm{~Pa}$ and a current of 15 to $35 \mathrm{~mA}$ showed the 


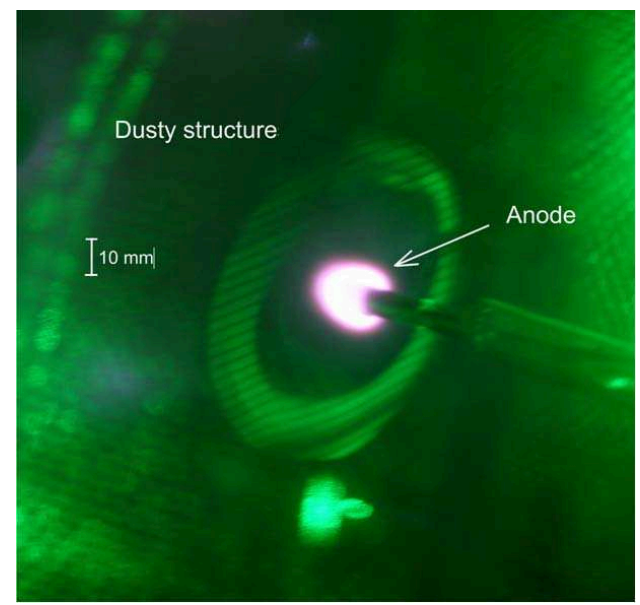

Fig. 1. Dusty structure in a spherical discharge in air (a gas pressure of $40 \mathrm{~Pa}$, and a discharge current of $35 \mathrm{~mA}$ )

spontaneous formation of dust structures from particles of unknown nature in 5-10 min after the discharge was turned on. In this case, the discharge was stratified, but the striations were not stable. The size of dust structures formed varied with the current and the discharge pressure from 3 to $10 \mathrm{~cm}$. Photographs of the sections of dust structures by a laser "knife" at various distances from the anode the in vertical and horizontal planes were made (Fig. 1). The particles were so tiny that they could not be seen separately. We try to observe the particles with a microscope with $65 \mathrm{X}$ magnification. But it was not possible to discern the particles separately even with a microscope. When the discharge was being turned-off, the structure was extending radially toward the cathode.

The matter of the origin of particles has not been resolved yet. It is possible to suggest that the particles appear to be the products of net dispersion under the action of gas ions. It can be proved by the fact that the particles appear not at once, some time is necessary for their formation.

In the course of the experiment, the recording of the air mass-spectrum from a discharge chamber was made aimed at the analysis of the influence a dust structure on the gas composition of the plasma-forming medium. Nevertheless, no changes in the air massspectrum were detected before and after the appearance of particles.

For the purpose of a controllable formation of dust structures, it is necessary to inject particles of the unknown behavior to the discharge. Soot particulates were chosen to be such particles, as they are small in size and mass (less than $1 \mu \mathrm{m}$ ).

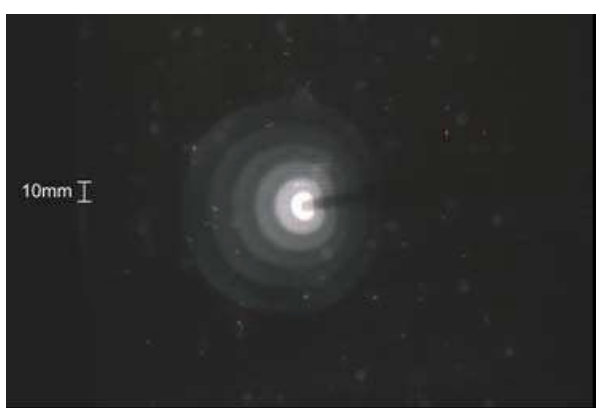

Fig. 2. Discharge in alcohol vapors (a gas pressure of $37 \mathrm{~Pa}$, and a discharge current of $31 \mathrm{~mA}$ )

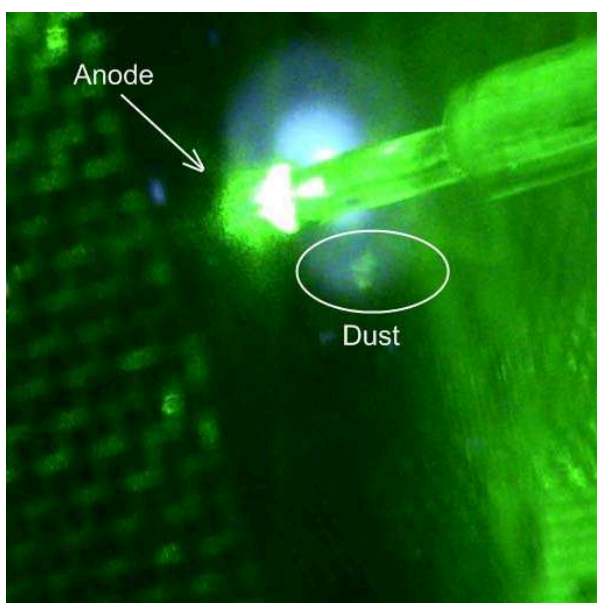

Fig. 3. Dusty structure in discharge strata (a gas pressure of 57 $\mathrm{Pa}$, a discharge current of $20 \mathrm{~mA}$ )

The experiments on the formation of dust structures from soot particulates were conducted in a stratified glow discharge. The stratified glow discharge was formed in alcohol vapors under differential pumping conditions. In this case, the gas composition in a discharge chamber was controlled with a mass-spectrometer. At the time of discharge, the gas medium is changed as a result of the molecular dissociation of high-molecular gases, which is expressed in an increase of the discharge chamber pressure and in changes in the discharge emission spectrum. A photograph of this stratified discharge is shown in Fig. 2.

As a result of the injection of soot particulate to the discharge, plasma-dust structures were formed from them. The structures hovered in discharge striations in the area located under the anode. Figure 3 shows the dust structures from soot particulates formed in a discharge. The illumination of the dust structures formed was provided by a laser "knife" of 200-mW 
power. The process of dust formation was being video recorded.

The results of the present work are as follows: spontaneously formed dust structures in a spherical glow discharge in air are observed, and the conditions of their existence are studied. The dust structures from soot particulates in a stratified spherical glow discharge in vapors of high-molecular substances are formed for the first time.

1. O.A. Nerushev, S.A. Novopashin, G.I. Sukhinin et al. Phys. Rev. E 58, 4897 (1998).

2. O.A. Nerushev, S.A. Novopashin, V.V. Radchenko et al. Plasma Phys. Rep. 26, 78 (2000).

Received 22.01.09
ФОРМУВАННЯ ПИЛОВИХ СТРУКТУР У СФЕРИЧНОМУ ЖЕВРІЮЧОМУ РОЗРЯДІ

\author{
А.І. Щербина, С.В. Бурдюх
}

$\mathrm{P}$ е $з$ ю м е

У даній статті вперше для формування i дослідження плазмово-пилових структур використано розряд сферичної геометрії. Плазмово-пилові структури можуть утворюватись довільно чи штучно. Утримування інжектованих пилинок відбувається у стратифікованому розряді високомолекулярних газів, таких як ацетон і етиловий спирт. У випадку плазми повітря генерація пилу відбувалася довільно і стратифікація розряду не спостерігалась. Експерименти було проведено при тиску газу 30-100 Па, розрядному струмі 20-30 мА. Контроль хімічного складу плазмоутворюючого газу відбувався за допомогою методів мас-спектрометрії. 